\title{
RESEARCH AND INDUSTRIAL \\ DEVELOPMENT OF SPACE RESOURCES
}

Alexander V. BAGROV, Doctor of Physical and Mathematical Sciences, Leading. Researcher, Institute of Astronomy RAS.

Moscow, Russia,

abagrov@inasan.ru
ABSIRACT I Humanity is ready to

development of space resounces, Today these look unusually attractive, but what possibitities of space exploration for

The most demanded mineral resourre which will be the sour of ygen and hydrogen, necessary forine 6 - eatning of astronauts and. jet engines. The Moon appears to be an equally valuable space resource as an extraterrestrial territory, on which

inhabited stations with completely controlled living conditions can be placed. Domestic cosmonautics can

begin to develop these resources in the near future:

Keywords: minerals, asteroids, comets, transportation

of asteroids, space exploration

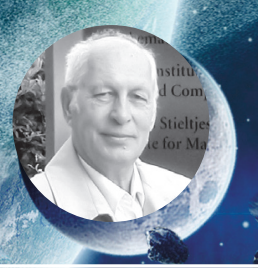

Александр Викторович БАГРОВ доктор физико-математических наук, ведущий научный сотрудник ФГБУН Институт астрономии PAH, Mockвer, Poccuras

abagrov@inasan.ru:f

\section{P.}

Анкб ТАция I Человечест̈во готово приступить к өсвоению ресурсов космоса. Эти ресурсы сегодня выглядят необыкновенно привлекательно, но каковы реальные возможности космонавтики ду их добычи? Самым востребованным минеральным ресурсом . восмосе является:вода; которая будет источнником khслородай водорода, необходимых для дыхания космонавтов и для реактивных двигателей. Не менее ценным ресурсом представляется Луна как внеземная территория, на которой могут быть размещены .7. ублтаемые станции сполностью контролируемыми ственिная көсџонавтика может приступить в самое близкое время.

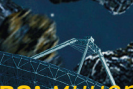
Ключевые слова: минеральне сырье, астероиды, космоса

иа астероидов, освоение

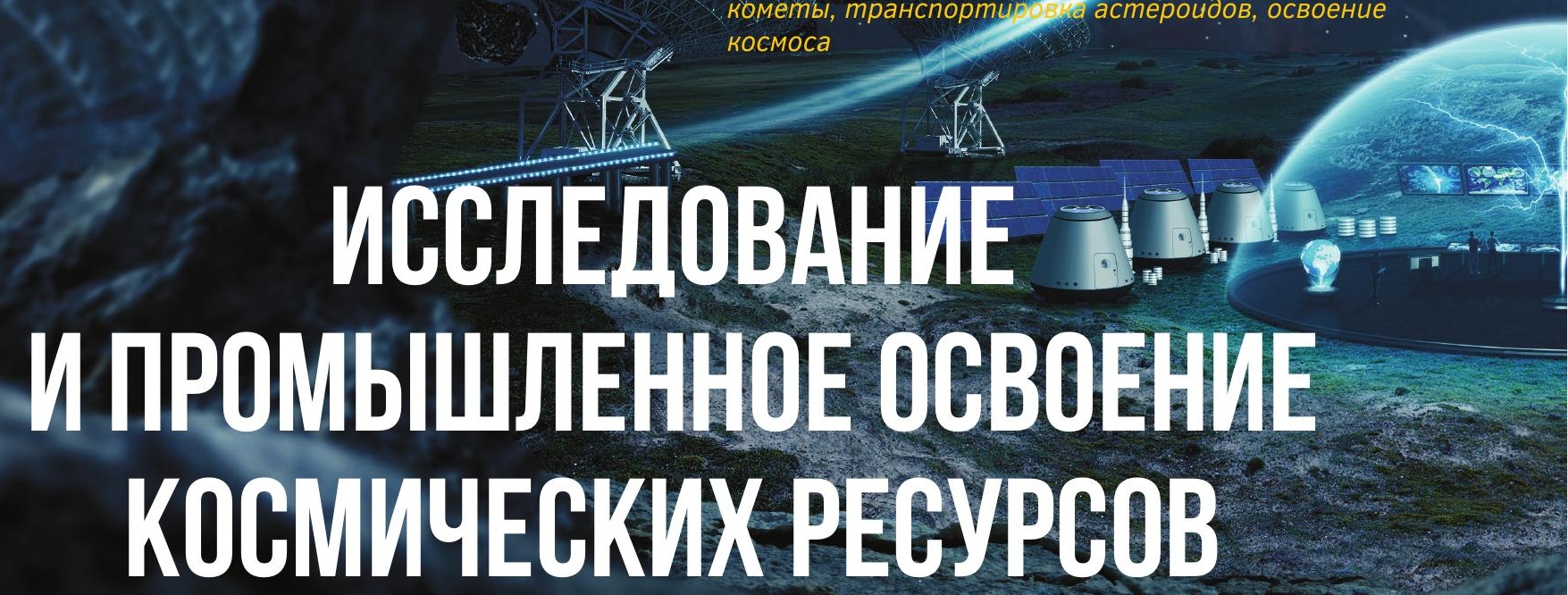




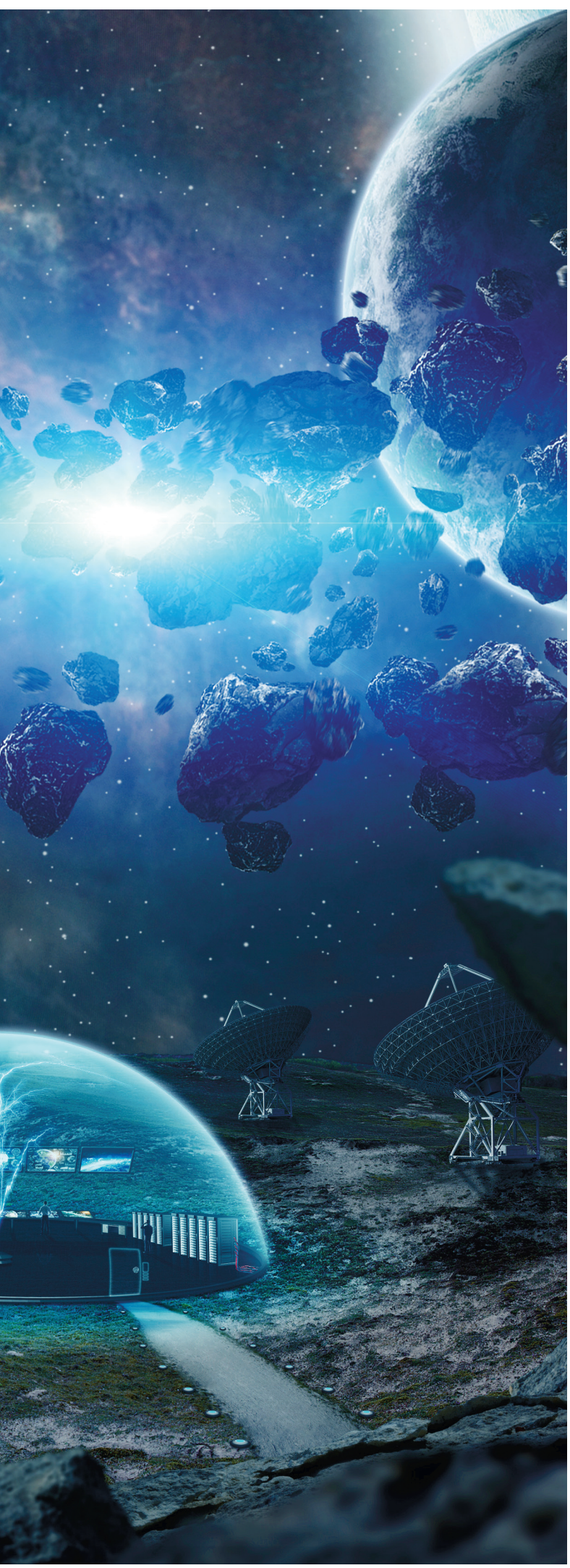

\section{ВВЕДЕНИЕ}

Малые тела Солнечной системы - в первую очередь очень многочисленные астероиды - по мере развития космической техники становятся все более привлекательными как источники сырьевых ресурсов [1]. На Землю из глубин космоса иногда прилетают метеориты, некоторые из которых состоят из чистого сплава железа с никелем и кобальтом [2]. Спектрофотометрические наблюдения астероидов показывают, что характер отражения их поверхностью солнечного света почти тот же, что и от поверхности метеоритов. Из этого делают вывод, что по своему составу астероиды должны быть идентичными метеоритам. Если это и в самом деле так, то астероиды могут стать очень серьезным конкурентом рудной промышленности. Сегодня мировое годовое производство железа оценивается в миллиард тонн [3]. Такое же количество железа может содержаться в одном астероиде диаметром около 300 метров. В Солнечной системе число астероидов такого размера оценивается в 750о, поэтому просторы космоса многим представляются современным нетронутым Клондайком. Кроме того, астероиды могут содержать большое количество редкоземельных элементов, в которых остро нуждается современная промышленность, и даже драгоценные металлы, которые сами по себе имеют высокую коммерческую стоимость.

\section{Мировое производство железа оценивается в миллиард тонн в год. Такое же количество железа может содержаться в одном астероиде диаметром около 300 метров.}

Большая часть астероидов Солнечной системы находится в так называемом Главном поясе астероидов, расположенном между орбитами Марса и Юпитера. Но некоторая часть астероидов имеет орбиты, сближающиеся с земной орбитой и проходящие от нее на расстоянии нескольких миллионов километров. Эти астероиды могут представлять особый интерес, так как они существенно более доступны, чем астероиды Главного пояса.

НАСА уделяет большое внимание исследованию астероидов. Им был осуществлен ряд успешных миссий, положивших начало контактным методам изучения астероидов $[4,5$, 6]. НАСА также инициировало проработку проектов перехвата астероидов в дальнем космосе и буксировки в околоземное пространство с целью их промышленной утилизации. Японское агентство ЈАХА тоже провело успешную миссию «Хаябуса» к небольшому астероиду 25143 Итокава с возвращением капсулы с веществом астероида на Землю [7]. Тем не менее пока нет никакой уверенности в экономической целесообразности использования астероидов как сырьевых источников в открытом космосе. 


\section{1. СВОЙСТВА АСТЕРОИДОВ}

Сведения о физических и химических свойствах астероидов скудны и нуждаются в обновлении. Дистанционные методы изучения небесных тел, развитые в астрономии, позволяют изучать оптические свойства поверхности астероидов. В частности, все предположения о химическом составе астероидов основываются на сравнении спектров, полученных от астероидов и от метеоритов, чей состав достоверно известен. По спектрам только примерно 70\% астероидов удается подобрать аналоги метеоритного вещества, но и они - всего лишь косвенные признаки сходства между ними. Если придерживаться популярной среди астрономов идеи, что астероиды постоянно подвергаются ударам метеоритов и микрометеоритов, то легче предположить, что свойства поверхности астероидов характерны для накопленных на ней метеоритов, а не для основного тела астероида. Собственно, об этом же говорит и неоднородный цвет поверхности астероида 433 Эрос на снимках, полученных с близкого расстояния от него во время проведения американской миссии NEAR (рис. 1). Поэтому основанное на косвенных признаках мнение, что какой-то

.
Если придерживаться
популярной среди астрономов
пдеи, что астероиды постоянно
подвергаются ударам метеоритов
прикрометеоритов, то можно
поверхности астероидов характерны
для накопленных на ней метеоритов,
а не для основного тела астероида.

астероид состоит из чистого железа или из платины, требует тщательной проверки и даже для посылки $\mathrm{k}$ нему разведывательной миссии, не говоря уже о решении технически более дорогой и более сложной задачи перехвата астероида и доставки его в околоземное пространство.

Второе обстоятельство, сильно затрудняющее проектирование аппаратов для контактного изучения малых тел Солнечной системы, связано с противоречивостью современных представле- ний о структуре астероидов. Широко распространено мнение, что астероиды, испытавшие многочисленные соударения между собой (о чем говорят многочисленные кратеры ударного происхождения на их поверхности), должны были разрушиться в результате ударов и теперь представляют собой "груды камней», объединенных снова в одно тело силой взаимного тяготения осколков. Это более чем спорное мнение, основанное лишь на немногих косвенных наблюдательных данных, с непонятным упорством применяется даже для объяснения структуры поверхности детально обследованных астероидов.

Очень натянутым кажется утверждение японских исследователей, что астероид 25143 Итокава тоже представляет собой «груду камней». Для этого они были вынуждены предположить, что вся мелкая фракция «осколков» ровным слоем засыпала одну часть астероида, а в других частях не сохранилась (рис. 2). А сделать вывод, что поверхность астероида целиком твердая и не содержит мелкого реголита, японские исследователи не посмели. Кстати, исследования лунной поверхности ясно показали, что слой лунного реголита очень тонок, даже в условиях намного более сильного лунного тяготения, а с поверхности мелких астероидов пылинки должны выбиваться даже ударами микрометеоритов.

С точки зрения космонавтики, очень важным является то свойство астероидов, что на их поверхности совершенно ничтожная сила тяжести, на уровне единиц сантиметров в секунду за секунду. При таком ускорении свободного падения даже небольшое усилие может выбросить весь аппарат за пределы области притяжения астероида. С подобной проблемой столкнулись разработчики миссии «Розетта» Европейского космического агентства (EKA), когда проводили посадку модуля «Филы» на поверхность кометы 67/Р Чурюмова-Герасименко. Небольшая посадочная скорость аппарата оказалась достаточной, чтобы силы упругости отбросили его с поверхности кометного ядра, и только после нескольких прыжков "Филы» остановился совсем не в том месте, где планировалась его мягкая посадка. Конструкторы из ЕКА неверно оценили прочность пылевого слоя на поверхности кометного ядра, и специальные винтовые якоря даже не смогли зафиксировать посадочный модуль в выбранном месте.

Между прочим, по этой же причине низкого тяготения на астероидах следует отнестись с недоверием к самой идее, что разрушенные в результате взаимных столкновений на множество осколков астероиды могли вновь собраться в единое тело «под действием взаимного притяжения». Сила притяжения между отдельными камнями совершенно ничтожна, и ее действия просто не могло 


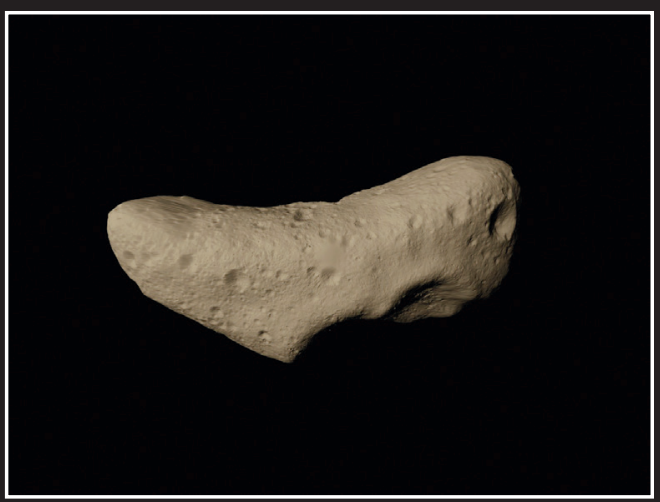

Рис. 1. Фотографбия астероида 433 Эрос (миссия NEAR, NASA)

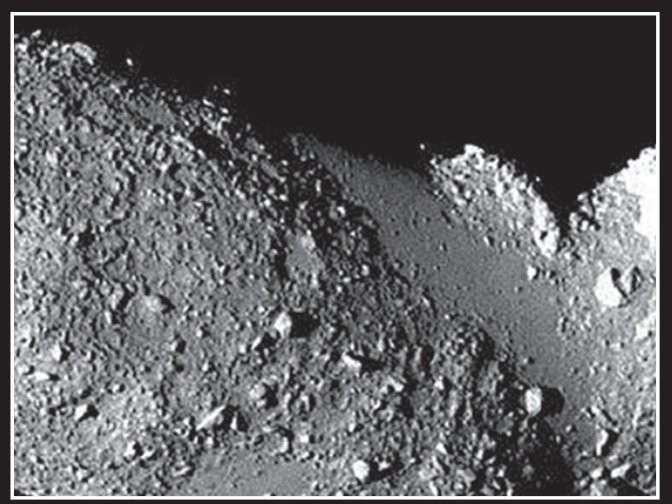

Рис. 2. Поверхность астероцда 25143 Итокава, на которой имеются участки с россыпями камней, а также участки с ровной поверхностью хватить на то, чтобы затормозить разлетающиеся осколки. Да и скорость разлета осколков во много раз была больше, чем «вторая космическая скоросты» для астероидов, которая составляет несколько сантиметров в секунду. Скорее всего, астероиды Главного пояса представляют собой монолитные тела из застывших расплавов [8].

Эти примеры ясно показывают, что точное знание свойств поверхности астероидов - обязательное условие проведения к ним исследовательских миссий, не говоря уже о решении задачи буксировки астероида. Отсюда следует преждевременность планов по использованию ресурсов космоса, имеющихся в астероидах.

\section{2. ТЕХНИЧЕСКИЕ ПРОБЛЕМЫ ПОСАДКИ НА АСТЕРОИДЫ И РАБОТЫ НА ИХ ПОВЕРХНОСТИ. СИСТЕМЫ ПРИЧА- ЛИВАНИЯ К АСТЕРОИДАМ И КОМЕТАМ}

Судьба посадочного модуля "Филы» миссии «Розетта» показывает, что для проведения полноценных исследовательских миссий к астероидам и кометам нужно создать систему причаливания к небесному телу малой массы, которая была бы в равной степени эффективной как для монолитного астероида, так и для рыхлого ядра кометы или гипотетической груды камней. В этом направлении НПО Лавочкина имеет серьезный задел. При подготовке миссий к Луне и Марсу была разработана техника для жесткой посадки контейнеров с научной аппаратурой (пенетраторов) на скорости в сотни метров в секунду. Сейчас мы продвинулись еще дальше и нашли способ безопасной доставки самой деликатной научной аппаратуры на поверхность исследуемых тел после столкновения с ней контейнеров с космической скоростью в несколько километров в секунду [9].

\section{3. ЧАСТНЫЕ КОМПАНИИ В КОСМИЧЕСКОЙ СФЕРЕ}

Космические исследования - это едва ли не самая дорогая область человеческой деятельности. Во времена Группы изучения реактивного движения (ГИРД) можно было ставить эксперименты и проводить разработки реактивных снарядов почти на чистом энтузиазме, но создание технологии космических полетов потребовало привлечения гигантских ресурсов на государственном уровне. Частные компании появились только тогда, когда космическая деятельность начала приносить прибыль. Но и эти компании существуют только благодаря мощной государственной поддержке, которая начинается с безвозмездной передачи компаниям созданных технологий и заканчивается государственными заказами на осуществляемую деятельность. Даже американский мультимиллиардер Илон Маск на свои средства не мог бы вести дорогостоящие разработки - все они ведутся за счет заказов НАСА, то есть за счет американских налогоплательщиков. Можно даже сделать вывод, 
что частные компании в космической сфере это немного завуалированный вариант передачи прибыльных государственных отраслей в частные руки. Сказанное относится и к частным компаниям, объявившим о своих планах освоения ресурсов космоса. За спиной у всех таких компаний стоят мощные государственные структуры. Правительствам выгодно, чтобы проблемными операциями в космосе занимались частные компании, так как в их частные дела государство "не вмешивается» и ответственности за их деяния не несет, хотя все, что эти компании делают, инициируется и оплачивается государством.

\section{4. ЮРИДИЧЕСКИЕ ВОПРОСЫ ИСПОЛЬЗОВАНИЯ КОСМИЧЕСКОГО ПРОСТРАНСТВА}

Вполне понятно желание космических держав оправдать огромные финансовые вложения в исследования, без которых невозможно начинать промышленное освоение ресурсов космоса, и в саму добычу этих ресурсов, если нет гарантий возврата вложенных средств через реализацию добытых ресурсов. Со времен принятия Договора о принципах деятельности государств по исследованию и использованию космического пространства, включая Луну и другие небесные тела, в 1966 году не было достигнуто международных договоренностей о формировании интернационального "космического права", защищающего космос от разграбления [10]. В чем состоит разница между сбором образцов лунных пород американскими космонавтами и захватом целого астероида в транспортировочный контейнер, предусмотренного в проекте Asteroid Redirect Mission [4]? Складывается впечатление, что за 50 лет после заключения Договора 1966 года не было результативной юридической работы

Отсутствие законодательных основ, определяющих порядок освоения космического пространства и ответственность за его нарушение, допускает весьма вольную трактовку принципа, провозглашающего космос «достоянием всего человечества». над космическим законодательством именно из-за надежд космических держав сначала захватить внеземную территорию и ее ресурсы, а потом узаконить захват по положению римского права «пусть каждый владеет тем, чем владеет».

К промышленному освоению космоса еще никто не приступил, но уже сегодня начался поток провокаций, которые в будущем могут стать причиной серьезных конфликтов. Отсутствие законодательных основ, определяющих порядок освоения космического пространства и ответственность за его нарушение, допускает весьма вольную трактовку принципа, провозглашающего космос «достоянием всего человечества», без какой бы то ни было дискриминации, на основе равенства всех стран и народов. Правительство США демонстративно пренебрегло этим принципом и приняло в 2015 году закон HR 2262, дающий гражданам США права на владение ресурсами, добытыми ими вне границ планеты Земля. Аналогичный закон на основании внутреннего законодательства принят правительством Люксембурга в 2017 году. Эти «законы», по своей сути, декларируют право отдельной страны на распространение собственного законодательства на осваиваемые территории космических тел.

Совершенно ясно, что отсутствие норм международного космического законодательства реально тормозит активность в освоении ресурсов космоса.

\section{5. ПЛАНЕТЫ И КОМЕТЫ - РЕСУРСНЫЕ КЛАДОВЫЕ КОСМОСА}

Нам представляется наиболее реалистичным освоение минеральных ресурсов Луны и комет. Основным минералом, слагающим многокилометровую кору Луны, является базальт. Он наполовину состоит из окислов кремния и наполовину из окислов металлов (железа, титана, магния, алюминия и пр.). При наличии огромных энергетических ресурсов в виде постоянного потока солнечной энергии будет экономически оправданна добыча металлов из лунного грунта и попутного получения кислорода. Металлы (как конструктивные материалы) и кислород (как окислитель для ракетного топлива и необходимый для дыхания космонавтов газ) сделают их добычу на Луне рентабельной в самом недалеком будущем. Оговоримся: эта "рентабельность» означает, что добыча минеральных ресурсов на Луне для нужд лунной промышленности будет эффективнее, чем их доставка на Луну с Земли, а вот польза от поставки из космоса сырья для земной промышленности - вопрос спорный.

Одним из важнейших ресурсов, в которых нуждается космонавтика, является вода. Один из самых дешевых продуктов на Земле, вода становится поч- 
ти золотой после доставки ее в космос. Астрономы утверждают, что на Луне могут существовать большие запасы водяного льда в тех местах, в которые никогда не попадают солнечные лучи. Такие места могут находиться в долинах среди гор в околополюсных областях. Правда, добыча льда там, где невозможно пользоваться солнечными батареями, может оказаться очень сложной задачей. Почти наверняка воду окажется проще добывать из комет, в которых она составляет до 80\% массы. В России уже разработан метод транспортировки кометных ядер с использованием солнечной энергии и вещества самой кометы для работы реактивного двигателя, и его можно будет применить для добычи водяного льда в космосе [11] .

При обследовании характерных для Луны горных территорий удобные ровные места для посадок можно подобрать, изучая детальные снимки лунной поверхности. В России уже предложены решения, которые обеспечат безопасную посадку практически в любом месте Луны [12]. Но вывести посадочный аппарат к этим точкам можно, только обладая хорошей системой координат. Сегодня система лунных координат имеет очень низкую точность; ошибка в определении местоположения по ним составляет сотни метров, а размер области, в которой может осуществиться посадка, составляет эллипс с размером 15×30 км. Представьте, как в такую область транспортировать детали будущей обитаемой станции, которые нужно будет найти, доставить в одно место и только после этого приступить к сборке станции! Поэтому вопрос о создании высокоточной и удобной в пользовании системы лунных координат стоит очень остро. В НПО Лавочкина разработано оригинальное решение этой проблемы с помощью световых маяков, которыми будут снабжаться все российские аппараты. После проведения миссий "Луна-25" и «Луна-26» российская космонавтика будет располагать системой координат, точность которой будет на уровне нескольких метров [13].

\section{6. КОСМИЧЕСКИЙ ТРАНСПОРТ}

Ракетная техника пока является единственным способом вывода кораблей и спутников в космос. Какой бы дорогой эта техника ни являлась, мы вынуждены мириться с этим, так как других способов добыть бесценные знания о космосе просто нет. Но когда пойдет речь о промышленной добыче ресурсов космоса и о колонизации небесных тел, положение изменится. Если добыча ресурсов и их доставка на Землю будут убыточны из-за дороговизны ракетной техники, то ими никто не будет заниматься. Без создания дешевых средств вывода полезной нагрузки в космос человечество обречено оставаться на Земле.
Пока в мире не существует проработанных технологий, на которых можно будет создать транспортную систему для космоса в близком будущем. Скорее всего, придется использовать обычные реактивные двигатели, но энергию для их работы, горючее и окислитель стараться получать непосредственно в космосе. В этом плане могут оказаться перспективными идеи использовать вещество транспортируемых комет или астероидов для создания реактивной тяги, которые были предложены для противодействия опасным космическим объектам [14].

\section{7. ПИЛОТИРУЕМАЯ КОСМОНАВТИКА}

Длительные перелеты к астероидам и кометам будут оставаться неопределенно долго недоступными для пилотируемой космонавтики. Уровень космической радиации за пределами магнитного поля Земли настолыко высок, что смертельную дозу радиационного облучения космонавты получат задолго до достижения целей своего полета. Создать надежную защиту от радиации можно, но масса защитной оболочки в десятки раз превысит массу самого корабля, а способов изготовления эффективной и легкой защиты от радиации наука пока представить не может. Следовательно, участие космонавтов в добыче космических ресурсов на астероидах, кометах и планетах нереально. Вместе с тем полностью автоматизировать сложные работы по добыче минерального сырья в дальнем космосе тоже не представляется возможным в ближайшие десятилетия. Так что при освоении ресурсов космоса придется ориентироваться на доставку астероидов и кометных ядер в околоземное пространство автоматическими аппаратами, а разработку сырья из этих космических тел вести вахтовым методом, гарантирующим безопасность космонавтов.

В недрах Луны, под защитой толстого слоя лунного грунта, космическая радиация не представит никакой опасности. Поэтому добыча минерального сырья в лунных шахтах может оказаться намного более перспективной, чем на астероидах.

\section{ЗАКЛЮЧЕНИЕ}

Долгосрочные планы освоения космоса и использования его ресурсов не могут быть конкретными на период свыше 30 лет. На больший срок можно ставить целевые ориентиры и приоритеты. Главным приоритетом России будет Луна. Основные усилия Россия направит на подготовку к освоению лунных ресурсов и на адресные исследования отдельных астероидов. 


\section{Литература}

1. Шустов Б.М. Космические ресурсы для развития экономики и науки // Воздушно-космическая сфера. 2019. № 4. С. 46-54.

2. Маров М.Я. Космос: от Солнечной системы вглубь Вселенной. М.: ФИЗМАТЛИТ, 2016. 536 с.

3. Текущие запасы железной руды, содержание железа и среднегодовое производство товарной железной руды в мире [Электронный ресурс] // Эксперт Online. URL: http://expert.ru/ratings/table_103839/ (Дата обращения: 06.03.2020).

4. What Is NASA's Asteroid Redirect Mission? URL: https:// www.nasa.gov/content/what-is-nasa-s-asteroid-redirectmission (Дата обращения: 06.03.2020).

5. The NEAR Mission. URL: http://near.jhuapl.edu/mission/ (Дата обращения: 06.03.2020).

6. Dawn Mission. URL: https://www.nasa.gov/mission_pages/ dawn/main/index.html (Дата обращения: 06.03.2020).

7. About Asteroid Explorer "HAYABUSA" (MUSES-C). URL: https://global.jaxa.jp/projects/sas/muses_c/ (Дата обращения: 06.03.2020).

8. Багров А.В. Первичная метеоритная бомбардировка // Жизнь и Вселенная / Ред. В.Н.Обридко и М.В.Рагульская. СПб: Изд-во ВВМ., 2017. С. 128-138. URL: http://www. izmiran.ru/pub/izmiran/Life-n-Universe.pdf

9. Патент № 2626792 РФ. Способ доставки полезного груза в грунт небесного тела, обеспечения исследований грунта и небесного тела и устройство его реализации (варианты) / Шалай В.В., Пичхадзе К.М., Багров А.В., Леун Е.В. Сысоев В.К., Вятлев П.А., Крупников В.И.; опубл. 01.08.2017. Бюллетень ФИПС «Изобретения, полезные модели» № 22.

10. Багров А.В. Как поделить Луну? // Воздушно-космическая сфера. 2019. № 3. С. 27-35.

11. Багров А.В., Леонов В.А., Кислицкий М.И. Промышленная заготовка водяного льда в космосе // Воздушно-космическая сфера. 2019. № 1. С. 76-81.

12. Багров А.В., Вятлев П.А., Сергеев Д.В., Сысоев В.К. Концепция обеспечения посадки лунных посадочных станций посредством светотеневого анализа видеоизображения подстилающей поверхности // Вестник ФГУП «НПО им. С.А. Лавочкина». 2012. № 5. С. 47-52.

13. Багров А.В., Дмитриев А.О., Леонов В.А. и др. Система глобального позиционирования для Луны на основе активных световых маяков // Вестник НПО имени С.А. Лавочкина. 2017. № 4. C. $5-10$.

14. Патент № 2504503 РФ. Способ ударного воздействия на опасные космические объекты и устройство для его осуществления / Багров А.В., Кислицкий М.И.; опубл. 10.09.2013. Бюллетень ФИПС «Изобретения, полезные модели» № 25 .

\section{References}

1. Shustov B.M. Kosmicheskie resursy dlya razvitiya ekonomiki i nauki. Vozdushno-kosmicheskaya sfera, 2019, no 4. pp. 46-54.

2. Marov M.Ya. Kosmos: ot Solnechnoy sistemy vglub' Vselennoy. Moscow, FIZMATLIT, 2016. 536 p.

3. Tekushchie zapasy zheleznoy rudy, soderzhanie zheleza i srednegodovoe proizvodstvo tovarnoy zheleznoy rudy v mire. Ekspert Online. Available at: http://expert.ru/ratings/table_103839/ (Retrieval date: 06.03.2020).

4. What Is NASA's Asteroid Redirect Mission? Available at: https:// www.nasa.gov/content/what-is-nasa-s-asteroid-redirect-mission (Retrieval date: 06.03.2020).

5. The NEAR Mission. Available at: http://near.jhuapl.edu/mission/ (Retrieval date: 06.03.2020).

6. Dawn Mission. Available at: https://www.nasa.gov/mission_pages/ dawn/main/index.html (Retrieval date: 06.03.2020).

7. About Asteroid Explorer "HAYABUSA" (MUSES-C). Available at: https://global.jaxa.jp/projects/sas/muses_c/ (Retrieval date: 06.03.2020).

8. Bagrov A.V. Pervichnaya meteoritnaya bombardirovka. Zhizn' i Vselennaya. Eds. V. N. Obridko, M. V. Ragul'skaya. Saint Petersburg, VVM Publ., 2017, pp. 128-138. Available at: http://www.izmiran.ru/ pub/izmiran/Life-n-Universe.pdf

9. Shalay V.V., Pichkhadze K.M., Bagrov A.V., Leun E.V. Sysoev V.K., Vyatlev P.A., Krupnikov V.I. Sposob dostavki poleznogo gruza v grunt nebesnogo tela, obespecheniya issledovaniy grunta i nebesnogo tela i ustroystvo ego realizatsii (varianty). Patent RF № 2626792 (2017).

10. Bagrov A.V. Kak podelit' Lunu? Vozdushno-kosmicheskaya sfera, 2019, no. 3, pp. 27-35.

11. Bagrov A.V., Leonov V.A., Kislitskiy M.I. Promyshlennaya zagotovka vodyanogo l'da v kosmose. Vozdushno-kosmicheskaya sfera, 2019, no. 1. pp. 76-81.

12. Bagrov A.V., Vyatlev P.A., Sergeev D.V., Sysoev V.K. Kontseptsiya obespecheniya posadki lunnykh posadochnykh stantsiy posredstvom svetotenevogo analiza videoizobrazheniya podstilayushchey poverkhnosti. Vestnik FGUP „NPO im. S.A. Lavochkina“, 2012, no. 5, pp. 47-52.

13. Bagrov A.V., Dmitriev A.O., Leonov V.A. et al. Sistema global'nogo pozitsionirovaniya dlya Luny na osnove aktivnykh svetovykh mayakov. Vestnik NPO imeni S.A. Lavochkina, 2017, no. 4, pp. 5-10.

14. Bagrov A.V., Kislitskiy M.I. Sposob udarnogo vozdeystviya na opasnye kosmicheskie ob"ekty i ustroystvo dlya ego osushchestvleniya. Patent RF № 2504503 (2013).

(C) Багров А.В., 2020

История статьи:

Поступила в редакцию: 12.02.2020

Принята к публикации: 27.02.2020

Модератор: Дмитрюк С.В.

Конфликт интересов: отсутствует

Для цитирования:

Багров А.В. Исследование и промышленное освоение космических ресурсов // Воздушно-космическая сфера. 2020. № 1. С. 90-96. 
Распоряжением Минобрнауки России от 12 февраля 2019 г. № 21-р журНал «ВКСп включең в Перечень научнььх изданий, рецензируемых Высшей алтестационной комиссией, в которых должны быть опубликованы основны научнье резульаты диссертаций на соискание ученой степени Доктора науу по научной специальности и соответствующей ей отрасли науки,05,07.10-Инновационные технологиив аэрокосмической деятельности (технические науки).

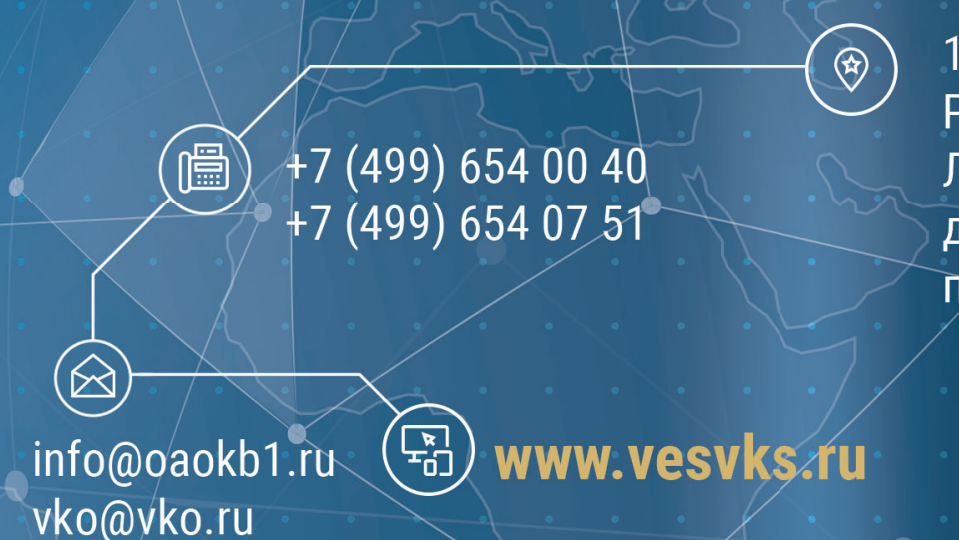

125190, Россия, Москва, Ленинградский пр., А. 80, корп. 16 , подъезд 1 vko@vko.ru

«ВКС» - печатный орган
Вневедомственного экспертного совет
по вопросам воздушно-космической

«ВКС» - печатный орган
Вневедомственного экспертного совета
по вопросам воздушно-космической

«ВКС» - печатный орган
Вневедомственного экспертного совет
по вопросам воздушно-космической сферы (ВЭС ВКС)

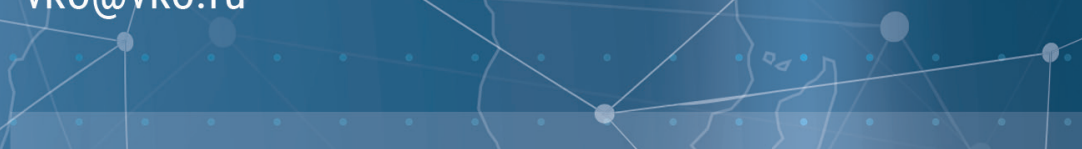

\section{Подписные индексы:}

Каталог «Роспечать» - 82530
Объединение профессионалов в области космонавтики И воздушнокосмической обороны 